\title{
The clinical challenge of mentalization-based therapy with children who are in 'pretend mode'
}

\begin{abstract}
The 'pretend mode' is one of the so-called "pre-mentalizing modes of thinking", which were first introduced by Target and Fonagy over twenty years ago. In a series of papers about play and reality, 'pretend mode' thinking was understood as a mode of pre-mentalizing thinking which is typical in the early years, but which can reappear in a more problematic way in adults. Although the concept of pretend mode was first introduced in a developmental context, as a clinical term it has primarily been discussed in the context of adult or adolescent psychotherapy. This paper suggests that the pretend mode is a valuable clinical concept for therapists working with school-age children, but that it's use in this context needs some clarification. After reviewing how pretend mode has been understood as a normal part of early development, this paper goes to demonstrate the various roles of pretend mode in clinical work with school-age children, and sets out a number of clinical strategies that may be used in therapeutic work.
\end{abstract}

\section{Key words:}

Pretend mode, mentalization, mentalization-based therapy, school-age, psychotherapy

\section{Introduction}

The 'pretend mode' is one of the so-called "pre-mentalizing modes of thinking", which were first introduced by Target and Fonagy over twenty years ago (1996). In a series of papers about play and reality, 'pretend mode' thinking was understood as a mode of pre-mentalizing thinking which is typical in the early years, but which can reappear in a more problematic way in adults. In particular, Target and Fonagy focused on 'pretend mode' as part of the clinical presentation of adults with a diagnosis of Borderline Personality Disorder, suggesting that this style of thinking could be understood as a way of separating mental states from internal (or external) reality, and used as a way to avoid facing painful internal or external realities. In line with this way of thinking, the definition of pretend mode in the Handbook of Mentalizing in Clinical Practive (Allen \& Fonagy 2008 
is "a mental state that is decoupled from reality yet, unlike in mentalizing, is not flexibly linked to reality" (p.515).

Building on this conceptual foundation, Bateman and Fonagy (2006) proposed that pretend mode is often evident in adult psychotherapy, in the form of intellectualizing, or using psychobabble, rather than genuine mentalization. When in 'pretend mode', according to the theory, the mental world is decoupled from reality or becomes more real than reality. When this happens, ideas no longer form a bridge between inner and outer reality. As Bateman puts it, when in pretend mode, it may sound like someone is genuinely mentalizing (e.g. they might be talking about seeing things from someone else's perspective), but as a listener the therapist might find that he or she cannot resonate with the feelings underlying these mentalizing efforts, as if something is being avoided and held apart. This has sometimes been called 'Elephant in the Room' thinking (Keaveny et al., 2012), because of the feeling in therapy that nothing genuine is really being engaged with, even if on the surface it may sound as if mentalizing is taking place. Sometimes pretend mode takes the form of an excessively intellectual approach, as if the person in pretend mode can't integrate the cognitive interpretation of emotional experiences with the bodily sensations associated with them.

Although the concept of pretend mode was first introduced in a developmental context, as a clinical term it has primarily been discussed in the context of adult or adolescent psychotherapy (Bateman and Fonagy 2016). In this paper, we want to suggest that the pretend mode is a valuable clinical concept for therapists working with school-age children, but that it's use in this context needs some clarification. As the term was originally used in a developmental context, this paper will begin by reviewing how pretend mode has been understood as a normal part of early development, before considering the role of pretend mode in clinical work with school-age children.

\section{Pretend mode and pretend play from a developmental perspective}

In their major work on Affect Regulation, Mentalization and the Development of the Self, Fonagy et al. (2002) set out a developmental line of the capacity to mentalize. They suggest that between ages 2-5 there is usually a transition from a split mode of experience to mentalization. They argue that the very young child equates the internal world with the external, and they label this mode of thinking 'psychic equivalence' - in other words, what exists in the mind must exist out there, with no room for alternative perspectives. The example they give of such 'normal' psychic equivalence is the child who imagines there is a monster under the bed, and therefore believes that there really is a monster 
there. At that moment, there is no space for a sense of pretend, or any gap between what is thought and what is perceived to actually be.

In a series of important papers, Fonagy and Target (1996) set out the way in which the child gradually learns how to 'play' with reality. Drawing on the work of child development researchers, they argue that with pretend play, a developmental step is taken towards replacing immediate action with mental activity (Reddy, 2008). From this perspective, play itself helps foster mental structures - "in play, it is as though [the child] were a head taller than himself" (Vygotsky, 1978). In pretend play, a chair is a tank and yet the child does not expect it to shoot real shells. A child can keep alternative or changing beliefs in mind if they are doing a task in play rather than for real. Drawing on Vygotsky's model of development, they argue that "play creates a zone of proximal development of the child... Action in the imaginative sphere, in an imaginary situation, the creation of voluntary intentions, and the formation of real-life plans and volitional motives - all appear in play and make it the highest level of preschool development" (Fonagy et al., 1996, p.261). From this perspective the child is 'taller' because he or she can partially free representations from their referents, so these representations can be modified in a more flexible mode of thought that encourages emergence of mental structures. In play, even young children have a mentalizing model of psychic experience - they can see the mind as representing ideas, desires and other feelings. Pretend mode allows a child to play with ideas, but also maintains omnipotence and compensates for life's frustrations.

Developmental researchers have identified a clear 'developmental line' for the capacity for pretend play. By 24 months, one ordinarily finds a range of pretend behaviours, and by 30 months, children usually use the term 'pretend' and understand that, when others are playing, it is not 'real' (Ensink and Mayes, 2010). A child learns to mentalize by playing. Hughes and Dunn (1997) show how pretending together as a family makes the mental world real, because the pretend world that is created is independent of the physical world, yet socially shared. It is no coincidence that the age of 2-3 is usually the phase when fantasy play comes to the fore - the parents and the child pretend, they are playful, but the boundary between external reality and pretend world needs to be maintained by the parents. As Fonagy et al. (2002) put it: 'The pretend mode of mentalizing involves an awareness of the representational nature of internal mind states: by separating or decoupling the mental states from reality, the child can differentiate thoughts and fantasies from actual reality, although on his own he can create no useful connection between this representation and reality' (p.293). 
As the quotation above makes clear, in pretend mode, a young child may be able to use mental states, but only when they are kept separate from external reality. If the boundary is not maintained, the child stops playing. If a parent comes along and asks, "Is that a tank, or is it a chair?", then the pretend mode will probably be broken, and the child's play is likely to come to an end. As such, the capacity for play has an inherently relational context.

But relationships are also what foster play and the developing mind. The capacity develops via interactions with a playful caregiver who reflects the child's thoughts/feelings in a marked manner. A caregiver can help a child to play by engaging with the world of play, elaborating it, and extending it.When this process proceeds smoothly, then normally, by the age of 4 , the child integrates these two modes (psychic equivalence and pretend mode) to arrive at mentalizing. Once this has been achieved, thoughts and feelings can be explored, but also connected to external reality. This integration involves a certain giving up omnipotence, 'treating ideas as ideas' - i.e. as representations of both internal/external reality, neither equated fully with each other ("my thought is not the same as reality") nor dissociated ("my thought has a connection to reality").

From this point onwards, play helps to build the child's life. As the developmental researchers have demonstrated, pretend play is a core feature of friendships between age 4-5 (Dunn \& Brown, 1994), transforming the quality of friendships, fostering understanding of social rules, roles and other minds (Fonagy et al. 1996, p.47/48). Pretend play thus helps to establish the capacity for mentalizing, i.e. mental states can be experienced as representations, with inner and outer reality linked.

\section{Pretend mode in the context of therapy with school-age children}

When thinking about therapy with school-age children, how might we expect pretend mode to manifest itself? The following vignette indicates one way.

Anne, who is 9 years old, has lived for four years in two different foster families and now lives back with her biological mother, stepfather and her half-sister. The family plans a holiday, for the first time in her life. But things are not going well for Anne. Her mother has told her that if her behaviour does not get better she cannot come on holiday with the family. Instead she will have to go to her grandmother, whom she hates, as a punishment. The day after her mother say this to her, Anne comes for her weekly therapy session, and tells her therapist that she probably is going to stay at home while the rest of her family goes on holiday. To the therapist's surprise, she says this in a rather satisfied, almost triumphant, tone of voice. So the therapist asks: 
$T$ : So how did it come about that you aren't travelling with them?

Anne: Well, my mum said that when I do well at school I can come with the family and when I am not good at school and at home I have to go to my grandmother and I cannot go on holiday.

T: That sounds like a big punishment

Anne: I don't care

$T:$ No?

Anne: No I already have a plan to go to America with my friends

$T:$ When you are grown up?

Anne: No no no this year, to America, secretly. First we will go to Disneyland, and then we will sleep there and after that we will visit Justin Bieber, give him a lot of money and then we will put up our tent and make a fire and we will travel all around.

T: Seems like a dream holiday! You have a great imagination, you know.

Anne: No no no - this is going to happen!

From the perspective of mentalization theory, one could say that Anne is operating, at this moment, in 'pretend mode'. Anne appears to be losing herself in her imagination, and in this way avoiding the painful experience of rejection associated with the threat of being left behind while her family go on holiday. As therapists, we might wonder whether the reality of her life is maybe so difficult that she cannot make a connection between what is happening around her and her inner feelings. As with an adult, Anne has temporarily retreated into a pre-mentalizing style of thinking in which pretending is not used as a way to engage with reality, but as a way to hold it at bay.

\section{Challenging pretend mode while working with time-limited MBT-C}

How does this understanding of the role of pretend play and pretend mode in the development of the child's mind inform clinical practice, when using a mentalization-based approach? During assessment the therapist tries to get a picture of the mentalizing capacities of a child, trying to be aware when a child is operating in a mentalizing and pre-mentalizing mode, and what areas the child may find it especially hard to maintain their mentalizing capacity (Muller and Midgley, 2012; Midgley et. al. 2017).

For example, Kimberley, 11 years old, is picking a shell from a basket, to represent her mother, during the assessment session where she has been asked to create a family constellation using the objects in a basket on the table. Kimberley is an only child living with her mother and stepfather, who have both had severe psychiatric problems for many years. Kimberley is often sad and depressed. 
She is isolated and cannot connect with other children. Because she is with adults most of the time, when listening to her the therapist often feels that she can hear her parents' voices. The therapist is curious to understand what thoughts and feelings this child has, so asks:

T: Why did you choose this shell for mommy?

K: Because the colours you see, mommy loves colours and these colours are exactly what mommy likes. And when you move the shell, the colours move too. And here are little imperfections, because of the fights, and the problems, and the hurting of people. And these imperfections fit my mommy.

T: How do you notice your mommy has imperfections?

$K:$ Well, she has fights with my grandpa, with her mother, who is my grandmother of course, and her future husband, who called my father a beggar. My mother was very angry and dad wanted to hit him....

At this point Kimberley starts telling all kind of details about a firework, a man repairing a bicycle and her dog, which goes on for a while, and leaves her therapist feeling quite confused. Being half-aware that something has changed, the therapist tries to stop and name this shift:

$T:$... it looked like, while you were thinking about your dog, something seemed to happen. You seemed to get sad. Am I right?

K: Yes, Mira was my favourite dog, and when I was little I was bitten by a big dog and since then I am afraid of big dogs. Mira was very big but also very sweet, but you had to watch out when she farted

(They laugh together)

T: Did you notice it yourself, how you got sad?

K: Yes, I notice it in my voice and also I feel a block here [pointing to her throat]

$T$ : That is so special you can feel this - really good. And do you know what I also noticed from the outside? I saw something change in your eyes and I noticed myself thinking 'her tears are close'. I thought, maybe she feels like crying? Is that so?

K: Yes

T: And did you swallow your tears?

K: I try, but I keep feeling the block in my throat. The block stays right there which is annoying! 
In this example the therapist tries to focus on Kimberley's bodily sensations. She is very attentive to what she notices from the outside and stops Kimberley in her 'psychobabble', her adult-sounding version of the problems in her life, to try to help her focus on the here and now, on what she is experiencing in herself. This is a way to help a child become aware of her bodily signals and helps Kimberley to stop her pretend mode, trying to explain everything in a sophisticated, cognitive way what she thinks the therapist wants to hear, but disconnected from her feelings. Kimberley reacts immediately to the intervention of the therapist and appears to be able to notice these bodily sensations and become aware of her emotions. This is important information, especially in an assessment session, when a therapist is trying to understand how a child may be able to make use of her interventions. At the end of this exchange, for the first time in this session, Kimberley's expressed feeling was totally congruent with what she was saying. This suggested to the therapist that Kimberley could make use of therapy to gradually mentalize more effectively in relation to those areas of her experience which were most painful.

\section{Children who are stuck in pretend mode}

Pretend mode can be confused with 'good ability to play' - but actually when in pretend mode a child's play is usually rigid or monotonous. The child plays, but the play doesn't shift, feelings are kept at bay. Often humour is lacking, and the play lacks emotional resonance. There is a possible link to avoidant attachment, i.e. attachment deactivation strategies allow thinking to stay 'online', but in an overly cognitive and with a pretend mode quality.

When a child's mind is operating in this way, this might lead to a session in which the child is simply lining up toys, or painting decorative flowers all over the page, papering over any feelings so as not to think or feel (for more examples see Midgley et.al. 2017, p.159 or Verheugt-Pleiter et.a. 2008).

Children may use a lot of mental-state language, as in the example of Kimberley above, but without a meaningful link to reality, not in contact with their feelings. Or children may play in a sort of welladjusted way, but the play is not linked to primary experiences and in the relationship with the therapist there seems to be an avoidant tendency, keeping the other at a distance. Children who often operate in this way might have learned to regulate emotions outside relationships. They are pulled back from emotional engagement with others. In such cases, their pretend mode feels like a way of avoiding feelings in general. 
Fatima, a 7 year old girl, lived with her grandparents from age 3, because her parents had been very emotionally neglecting. Her father had used drugs in these early years of her live. In the beginning of therapy she seemed to play really nicely, especially with the animals in the sandtray. But she had difficulty playing together. The therapist became an active commentator, being curious about the play. Fatima could make sounds and little voices of the characters she played with, but there was no real emotion or involvement in her play.

One day Fatima wants the therapist to play with her but to do exactly what she wants. She tells which animals the therapist can have and she makes up the line of the story. It is a story about animals in large families, in different countries, wondering if it is safe or not, looking out for the bad guy. The bad guy could have been the good guy but changes suddenly into the bad guy. The therapist feels stuck in this story which they have played many times and feels she cannot make any reference to what the girl is playing. She tries to give words to the feelings of the animals in the play and asks Fatima about the thoughts or feelings of her animals. But Fatima seems to avoid these questions and the therapist is not sure if she hears her questions about what the animals might be feeling or thinking or wanting or longing for. She doesn't react much to what the therapist says.

Fatima's pretend play feels like a wall between them. The therapist feels bored in the play and not involved. She is puzzled because there is a lot of symbolic play which at first seemed meaningful. The therapist notices there is some tension in the demanding way Fatima can decide about the roles and the play, not allowing the therapist to add or change anything she hasn't got in mind. The therapist decides she wants to try to turn up the heat in the room and starts to frustrate Fatima a bit by using the same animal that Fatima usually wants. Fatima gets angry and doesn't want to play anymore. For the first time in weeks there is real emotion in the playroom. The therapist validates the feelings of frustration but doesn't give in. She wants Fatima and herself to find a solution for the problem of wanting to use the same animal.

After a while of sitting back Fatima suggests to take turnss in having the animal, which is a wonderful solution. After this 'clash' the therapist experiments in the relation with Fatima by stepping out of the play and focusing more on what is going on between them, turning up the temperature once again, and looking for ways to help Fatima really feel in the here-and-now and not avoid the feelings by playing and living in a fantasy-world. The therapist starts to add new perspectives in the play and for the first time Fatima is open to this input and reacts well. She starts to get more self-confidence, to wonder more about what she wants and why she wants to decide all the time. She starts to see herself from the outside. The therapist feels more engaged and feels real emotional contact and reciprocity. 
When working with children who are sometimes stuck in pretend mode, it is important to be aware of the arousal level. When the arousal level is too low it might help to turn up the level by paying special attention to body signals, to focus in the here-and-now of what a child is experiencing or what is going on in the therapeutic relationship. The therapist can find moments of shared attention and grasp them in an attempt to be in tune; or might learn more about a child's emotions by trying to playfully over-exaggerate, which can allow children to see themselves from the outside. But when the arousal level is too high and a child has difficulty to pretend, the therapist turns the emotional temperature in the room down and helps the child by empathic validation and thinking about creating a safe context to make a step forwards towards symbolic, pretend play.

In Fatima's case, above, the therapist felt that there was a need to 'turn up the heat', in order to challenge her pretend mode functioning. But the timing of turning up the heat, when working with children like Fatima, is very important because there is a risk of losing all contact with the child. Nevertheless, it is important for therapists to keep in mind that childeren who have faced adversity and have difficulties in their lives still have strenghts and resilience (Cooper and Redfern 2016), and that the therapist sometimes needs to take a risk and offer quite a robust response when the child is operating in pretend mode. Sometimes this may not be obvious at the start of the therapy but it is good to remember that the child has survived difficult experiences and may be stronger than you think. In working with Fatima, the therapist gradually became more confident in being playful and challenging. By the later stages of the therapy there was a shared understanding and with humor they could laugh together when Fatima 'definitely' wanted to have things her own way. By taking a risk and 'turning up the heat' at key moments, the therapist was able to challenge Fatima's 'pretend mode' functioning, and help her to become more able to take the perspective of others and engage in more reciprocal play.

\section{Children who struggle to establish pretend mode}

For children such as Fatima, operating in pretend mode can be a defence, and the therapist's task is to find the right moment and method to challenge this, so that a more mentalizing mode of relating can be established. But for children who have experienced complex, relational trauma, they may have little space for the distinction of inner and outer reality and can struggle to even establish a pretend mode way of operating (Fonagy et al. 1993). Faced by early relational trauma or abuse, often the only way to survive may have been to separate the connection between internal states and the intolerable external reality. For children such as this, there is no 'potential space' (Winnicott, 1971) within which to play. Often the traumatic events may have started before the development of 
language. These children cannot always tell or express coherently what they experience inside themselves because they lack the words or a narrative to help them understand why they are so hypervigilant or restless all the time (Vliegen et.al 2017). In therapy with these children, the challenge is to help the child establish pretend mode.

Children stuck in psychic equivalence may not dare to think in pretend terms, so their play is often very wild, chaotic and destructive; in games, losing is not acceptable (Zevalkink et al., 2012). Pretend play can become too realistic and the border between fantasy and reality is lost. Such a situation can be seen in the case of Mike, age 7, who was adopted at 5 with his twin sister, having been born in Eastern Europe and lived in an orphanage for the most part of their early lives. Mike cannot function well at school. He hits other children, screams really loudly when challenged, and has severe agressive outbursts. At home he can show a bit more of his anxiety but he also has big fights with his sister. He seems to lack a vocabulairy for his feelings. His adoptive parents love him very much and really try to understand him and his behaviour, but realise that he needs more help than they can offer on their own, so have brought him to see a therapist.

During the first asessment session with Mike there is total chaos in the room. Mike is destructive in his play, wants to touch everything, throws the toys, making a mess in the room, and finishing a drawing in two minutes. He has an attention problem and doesn't seem to know what he can do with the material. The therapist wonders to herself if this might be what Mike is experiencing inside: tension, restlessness and chaos. Is his behaviour an expression of his former experiences? Is this his way of expressing a part of the history of his life? Or is he acting as if whatever was in his mind reflected the reality of how things are 'out there' for him, threatening and destructive? He is not pretending, nor playing, and is not able to speak about himself. He doesn't seem to make a connection with the therapist.

After the first session the therapist feels exhausted and thinks that Mikehas been operating in psychic equivalence mode most of the time. He was unable to regulate himself and seemed overwhelmed by all the toys, possibilities and unspoken expectations in the playroom. When they next meet, the therapist first aims to try to down-regulate the affect, remembering Perry's dictum: "first regulate, then relate, then reason" (2016) . the therapist hopes that when Mike can experience a bit more safety in the room, he might become more connected in the moment and a bit more open. To help Mike to regulate himself the therapist decides to work with Mike in another room which is warm and colourful but with less distractions; the toys are behind closed doors and the room is less spacious and open. She also decides to help him choose between two things to do, 
which makes the session more predictable for him. She takes the lead, offering a setting where he could calm down a bit, trying to create an atmosphere of peace. In this way she is hoping to help him to relate to the material, to himself and eventually to the therapist.

Mike chooses to play with the wooden blocks. He starts to build a square. He enjoys the construction material, seems to love the feel of it and is more at ease. After this session he keeps wanting to build with the wooden blocks. The therapist helps him to experience in the here and now what he feels when he touches the wood, how it smells, and starts to ask him tentatively about what he would like to build with the blocks. Mike wants to build a stable for a horse. There are no windows and the door is blocked. The therapist doesn't try to explore the symbolic meaning of the play, but simply allows Mike to enjoy playing with the blocks for some time. The therapist tries to make some contact: enough to show her engagment but not too much to be overwhelming. She tries to use her vocal tone of voice to connect with him, especially to mark his emotional states, being very much aware of using these ostentive cues. This goes on for a few sessions.

After several weeks of such play, the therapist tries to invite Mike to be curious about the horse in his stable, rather than focusing on Mike and his mind. After a few weeks Mike suddenly tells the therapist he himself had to sit in a dark room in the orphanage many times, just like the little horse in his square, because he had not been listening to the nurses. After this disclosure he starts to construct windows in the stable and a door which he can open and close and he wants another horse to join in the stable. There is a beginning of pretend play and Mike is able to connect with his fears, his sadness and longing for contact in his play. He is also developing a sense of self-agency, being able to change the stable and creating a better place for the horse.

For most of her work with Mike, the therapist did not try to name or explore the symbolic meanning of his play, or to make links between Mike's play and his own experiences. She did this because traumatized children, who have not yet fully established the pretend mode, are vulnerable to experience expressions of emotions as overwhelming, when the as-if quality is lost and emotions are experienced as 'too real'. However, pretend play can be an opportunity for beginning a process of helping them to develop a sense of themselves as a person with a mind, by finding themselves in the mind of the therapist. The therapist's role then becomes an active commentator, trying to invite the child to expand the story, until they are themselves ready to integrate the pre-mentalizing modes (Zevalkink et al. 2012).

\section{Conclusion}


When working with primary-school age children, it is important to think developmentally about the child's use of pretend mode. In the literature on MBT with adults, the focus has been on pretend mode as a pre-mentalizing mode which has to be challenged in order to help the client regain their capacity to mentalize. But the situation is not quite the same when working with children. Sometimes a child whose capacity for mentalizing is still under-developed needs support to move from psychic equivalence into pretend mode. Or sometimes reality is too painful for a child and we mustn't challenge their urge to stay in pretend mode but instead accept it, and work with parents to create a safer context in which they live, so that the child is living in a safe enough context to afford to give up their pretend mode functioning.

For children who have established some capacity to mentalize, however, the therapist sometimes needs to challenge pretend mode thinking to help re-establish real mentalizing. These children may describe grandiose and self-serving descriptions of abilities and plans, and talk about how much others admire them, but without engaging with real issues, such as feeling insecure or anxious about being excluded. If one joins the pretend play, this might encourage pseudo-mentalization for children in pretend mode. So the challenge for the child therapist is to try to notice the pretend mode in the child - perhaps by noticing one's own feelings of boredom or a sense of working in 'autopilot' - and understand the function or meaning of this pretend mode for the child, or the environment in which the child lives.

\section{Literature}

Allen, J.G. \& Fonagy, P. (Eds.) (2006) Handbook of Mentalization Based Treatment. UK John Wiley and Sons Ltd.

Bateman, A. \& Fonagy, P. (2006) Mentalization-Based Treatment for Borderline Personality Disorder: A practical guide. Oxford, UK, Oxford University Press.

Bateman, A. Fonagy, P. (2016). Handbook of Mentalizing in Mental Health Practice. Washington DC American, Psychiatric Publishing Inc. 
Cooper, A. Redfern, S. (2016) Reflective Parenting; a guide to understanding what is going on in your child's mind. London Routledge.

Dunn, J. \& Brown, J. (1994 ). Affect expression in the family, children's understanding of emotions, and their interactions with others. Merril-Palmer Quarterly 40, 120-137

Ensink, K., \& Mayes, L.C. (2010). The development of mentalization in children from a theory of mind perspective. Psychoanalytic Inquiry, 30, 301-337. http://psycnet.apa.org/record/2010-14816-003

Fonagy, P., Edgcumbe, R., Moran, G., Kennedy, H., and Target, M. (1993). The roles of mental representations and mental processes in therapeutic action. Psychoanalytic Study of the Child 48, 9-48.

Fonagy, P. \& Target, M. (1996). Playing with reality I: Theory of mind and the normal development of psychic reality, in International Journal of Psycho-Analysis 77, p.217-233.

Fonagy, P., Gergely, G., Jurist, E., and Target, M. (2002). Affect Regulation, Mentalization and the Development of Self. New York, NY: Other Press

Hughes, C. \& Dunn, J. (1997). "Pretend you didn't know": Preschoolers' talk about mental states in pretend play. Cognitive Development, 12(4):477-497

Keaveny, E., Midgley, N., Asen, E., Bevington, D. Fearon, P., Fonagy, P. ....Wood,S.(2012). Minding the family mind: The development and initial evaluation of mentalization based treatment for families, in N. Midgley \& I. Vrouva (Eds.) Minding the Child: Mentalization-Based Interventions with Children, Young People and their Families, p.98-112. London, England: Routledge.

Midgley, N., \& Vrouva, I. (2012). Minding the Child: Mentalization-Based Interventions with Children, Young People and their Families. London: Routledge.

Midgely, N., Ensink, K., Lindqvist, K., Malberg, N \& Muller,N. (2017). Mentalization-Based Treatment for Children: A time-limited approach. Washington DC, American Psychological Association. 
Muller, N., Gerits, L., and Siecker, I. (2012). Mentalization-based therapies with adopted children and their families. In N. Midgley \& I. Vrouva (Eds.) Minding the Child: Mentalization-Based Interventions with Children, Young People and their Families, p.113-130. London, England: Routledge.

Perry. B. (2016). http://www.thetraumatherapistproject.com/podcast/bruce-perry-md-phd/.

Reddy, V.N.V.(2008). How infants know minds. Boston,MA, Harvard University Press.

Target,M. \& Fonagy, P. (1996). Playing with reality II: The development of psychic reality from a theoretical perspective, in international Journal of Psycho-Analysis 77, p.459-479.

Verheugt-Pleiter, A. J. E., Zevalkink, J., and Schmeets, M. G. J. (2008). Mentalizing in Child Therapy: Guidelines for Clinical Practitioners. London: Karnac

Vliegen, N., Tng, E., Meurs, P. (2017) Van kwetsuur naar litteken; hulpverlening aan kinderen met complex trauma. Pelckmans Pro Uitgevers NV.

Vygotsky, L.S. (1978). Mind in society: the development of higher psychological processes. Cambridge, M.A. Harvard University Press.

Winnicott, D. W. (1971). Playing and Reality. London: Routledge, 1971

Zevalkink, J., Verheugt-Pleiter, A., and Fonagy, P. (2012). Mentalization-informed child psychoanalytic psychotherapy, in A. Bateman and P. Fonagy (Eds.) Handbook of Mentalizing in Mental Health Practice, 129-158, Arlington, VA: American Psychiatric Publishing Inc. 